\title{
Experiencias de mujeres lesbianas en métodos de salud sexual e infecciones de transmisión sexual
}

Experiences of lesbian women in sexual health methods and sexually transmitted infections

\author{
Margarita Lazcano-Ortiz ${ }^{a}$, Karla Castillo-Quintero ${ }^{b}$, María de J. Cruz-Rodríguez ${ }^{b}$, Manuel A. \\ Gaspar-Juárez ${ }^{b}$, Martha Sevilla-Marcelo ${ }^{b}$, Daniela Trejo-Ojeda ${ }^{b}$, María L. Sánchez-Padilla $^{c}$
}

\begin{abstract}
:
Objective: To explore experiences in the use of sexual health methods and their relationship with Sexually Transmitted Infections in lesbian women. Material and Method: Qualitative research, with a phenomenological approach, sample of 10 participants with chain or network sampling technique, data were collected with semi-structured observation guide of 12 questions, identifying the participants with numbers from 1 to 10 delivering a informed consent. Results: Lesbian women have empirical knowledge of sexual health methods and recognize their importance but most of them do not carry a responsible sexuality, in their experiences and feelings they manifest greater pleasure and excitement without the use of a method, the little approach they have with health professionals, it is a good tool for counseling of adequate sexual health. Conclusion: Lesbian women have had few experiences regarding the use of sexual health methods, the probability of contracting an STI is relatively high, nursing has an important preventive work with lesbian women for healthy sexual health
\end{abstract}

\section{Keywords:}

Sexual health methods, Sexually transmitted infections, lesbians.

\section{Resumen:}

Objetivo: Explorar las experiencias en el uso de métodos de salud sexual y su relación con las Infecciones de Transmisión Sexual en mujeres lesbianas. Material y Método: Investigación cualitativa, con enfoque fenomenológico, muestra de 10 participantes con técnica de muestreo en cadena, se recolectaron los datos con guía de observación semiestructurada de 12 interrogantes, identificando a las participantes con numeración del 1 al 10 entregando un consentimiento informado. Resultados: Las mujeres lesbianas tienen conocimiento empírico de métodos de salud sexual y reconocen su importancia pero gran parte de ellas no llevan una sexualidad responsable, en sus experiencias y sentimientos manifiestan mayor placer y excitación sin el uso de un método, el poco acercamiento que tienen ellas con los profesionales de salud, es una buena herramienta para el asesoramiento de una adecuada salud sexual. Conclusión: Las mujeres lesbianas han tenido pocas experiencias con respecto al uso de métodos de salud sexual, la probabilidad de que contraigan una ITS es relativamente alta, enfermería tiene una importante labor preventiva con las mujeres lesbianas para una salud sexual saludable.

\section{Palabras Clave:}

Métodos de salud sexual, Infecciones de transmisión sexual, lesbianas.

\footnotetext{
${ }^{a}$ Autor de Correspondencia, Profesor Investigador, SNI, Universidad Autónoma del Estado de Hidalgo, Instituto de Ciencias de la Salud, Área académica de Enfermería, ORCID: 0000-0002-9653-9291. Pachuca Hgo. México, Email: margarita_lazcano@uaeh.edu.mx

${ }^{\text {b }}$ Alumnos de Licenciatura en Enfermería de la Universidad Autónoma del Estado de Hidalgo, Instituto de Ciencias de la Salud, Área académica de Enfermería, Pachuca Hgo. México. Email: margarita_lazcano@uaeh.edu.mx

c Profesor investigador Universidad Autónoma del Estado de Hidalgo, Instituto de Ciencias de la Salud, Área académica de Enfermería, Pachuca Hgo. México. Email: marialuisasanchezpadilla@yahoo.com.mx
} 


\section{Introducción}

El término lesbiana, hace referencia a la identidad de género de mujeres con una orientación sexual homosexual, es un término genérico para describir a personas (mujeres) que mantienen relaciones con personas de su mismo sexo [1]. El tema del lesbianismo siempre se ha considerado un tabú y a pesar de que se ha discutido con frecuencia los últimos años aún existe una gran ignorancia sobre este tema. Al darse cuenta del rechazo y aceptaciones por diferentes personas hacia la homosexualidad.

Las infecciones de transmisión sexual, son todas aquellas que se adquieren principalmente por contacto sexual, al tener relaciones sexuales sin protección y con una persona que está infectada, las cuales son causadas por: virus, hongos, bacterias y parásitos ${ }^{[2]}$.

En la actualidad, el uso de métodos de salud sexual es una práctica cotidiana que llevan a cabo algunas mujeres y hombres en una relación sexual. Sin embargo, aún persisten dudas al momento de elegir por el poco conocimiento de los diversos tipos de métodos que pueden ayudar a planificar antes del encuentro sexual permitiendo disfrutar de la ocasión sin preocupaciones ${ }^{[3]}$.

La enfermera cumple una importante labor preventiva como profesional de salud, al interactuar con la mujer lesbiana, se le brinda, además de la información, apoyo y orientación para que exprese sus dudas, temores, inquietudes, sentimientos, expectativas lo que favorece personalizar el contenido informativo y que sean ellas quien tomen decisiones a favor de su salud, de tal forma que sus enseñanzas los oriente a responsabilizarse activamente en la conservación de la salud, en éste caso a prevenir una ITS, incluido el VIH/SIDA ${ }^{[4]}$.

\section{Marco Teórico}

El lesbianismo se refiere a que las mujeres se ven atraídas sexual y amorosamente por otras mujeres. El término hace referencia directa a la homosexualidad entre mujeres la cual es comúnmente llamada así, es un término genérico para describir a personas que mantienen relaciones con las de su mismo sexo ${ }^{[5]}$. Las infecciones de transmisión sexual son aquellas que se trasmiten en forma predominante o exclusiva por contacto sexual ${ }^{[6] .}$ Las infecciones de transmisión sexual (ITS) sólo se van a diseminar en un grupo determinado de la población: los sexualmente activos y de allí su estrecha relación con el VIH ${ }^{[7]}$. Las ITS producen signos y síntomas como ulceras, verrugas, secreción uretral y vaginal, entre otros ${ }^{[6]}$. Entre las ITS se tiene a: sífilis, Gonorrea, Chancro, herpes, tricomoniasis, vaginitis bacteriana, papiloma humano, SIDA.

\section{Prácticas sexuales en lesbianas}

Culturalmente las prácticas sexuales han estado ligadas a la penetración, como si fuera la única práctica válida o la única finalidad en las relaciones sexuales. Incluso se habla de "preliminares" (besos, caricias, masturbación mutua...). Sin embargo, cualquier práctica sexual puede ser gratificante y estimulante ya que son expresiones de los propios deseos y afectos de las lesbianas. No todas las lesbianas viven la sexualidad de la misma manera y no existe una sola forma de practicar el sexo, se puede disfrutar y jugar según el momento: las ganas, deseos y preferencias de cada lesbiana puede variar en cada encuentro sexual ${ }^{[8]}$.

\section{Salud sexual en lesbianas}

Según la Organización Mundial de la Salud, la definición de ésta es "un estado de completo bienestar 
físico, mental y social, y no solamente la ausencia de afecciones o enfermedades".

Cuando hablamos de salud sexual nos referimos a sentirnos bien con nuestra sexualidad y gozar de ella, siguiendo unos principios de respeto hacia nosotros mismos y hacia las demás ${ }^{[8]}$.

La salud sexual es un derecho y ese derecho incluye tener información y recursos para decidir libre y responsablemente sobre la sexualidad, sin que se vean sometidas a ningún tipo de coerción, discriminación o violencia. Supone tener relaciones igualitarias asentadas en el respeto y reconocimiento mutuo en donde se pueda expresar libremente los deseos y límites, y que estos sean atendidos y respetados.

La vivencia de la sexualidad está íntimamente relacionada con el entorno. Cuanto mayor sea el rechazo que se sienta hacia la orientación sexual, más difícil resulta el cuidado de la salud sexual. Los mandatos de género, es decir, las expectativas que se tienen de las lesbianas por el hecho de ser mujeres, las colocan en situación de desigualdad. $Y$ es en ese contexto donde aprende como la heteronormatividad predominante en la sociedad excluye otras opciones diferentes o igual de válidas, como el ser lesbianas o bisexuales, y es también dónde se construye la sexualidad y se aprende lo que se debe sentir y cómo deben relacionarse ${ }^{[8] \text {. }}$

\section{Rol Educativo de la Enfermera en la Prevención de las ITS y VIH-SIDA.}

La enfermera cumple una importante labor preventiva como profesional de salud, al interactuar con la mujer lesbiana, se le brinda, además de la información, apoyo y orientación para que exprese sus dudas, temores, inquietudes, sentimientos, expectativas lo que favorece personalizar el contenido informativo y que sean ellas quien tomen decisiones a favor de su salud, de tal forma que sus enseñanzas los oriente a responsabilizarse activamente en la conservación de la salud, en éste caso a prevenir una ITS, incluido el $\mathrm{VIH} / \mathrm{SIDA}^{[4] \text {. }}$

La enfermera educa a la persona acerca de la manera de reducir los comportamientos de riesgos y da a conocer las medidas de prevención, de cómo limitar el número de compañeros sexuales, utilizar el condón de manera adecuada., orienta sobre la abstinencia sobre la necesidad de ser responsable con el compañero sexual (fidelidad), entre otros ${ }^{[9]}$

La participación educativa de la enfermera se reafirma en la Estrategia Sanitaria Nacional de Prevención y Control de las ITS y VIH/SIDA, donde se considera tres Líneas de Acción siendo una de ellas la de Prevención y Promoción. Se enfatiza en que la enfermera, entre otras actividades, brinda educación a la población, especialmente, a los adolescentes y jóvenes sobre las ITS, su transmisión, enfatizando en las medidas preventivas; incluidas el VIH/SIDA ${ }^{[9]}$.

\section{Medidas Preventivas de ITS/VIH-SIDA}

Son todas aquellas medidas usadas con el fin de prevenir el contagio de las ITS, entre las cuales se tiene:

- Practicar el "sexo seguro". Es toda práctica sexual en la que no se está en contacto con fluidos que son de riesgo: semen, secreciones vaginales, sangre. Existen varias alternativas y estas son: masturbación, caricias, besos, masajes eróticos e incluso el uso del preservativo. Tienen como propósito de reducir el riesgo a contraer SIDA u otra enfermedad de transmisión sexual.

- Uso correcto del preservativo en las relaciones sexuales. Es la manera más efectiva de prevenir las ITS, usarlo en toda relación sexual; es necesario comprobar que el preservativo o condón esté en buenas 
condiciones, es decir, no usar si el envase está roto o despegado, está resquebrajado, reseco o pegajoso, el color está alterado o es desigual.

- Prácticas sexuales sin penetración. Son aquellas prácticas en las cuales no existe el coito (penetración), entre ellas, están los besos, fantasear, los abrazos, las caricias

- Ser fiel a la pareja o pareja sexual única y duradera. Esto hace referencia a "tener.

\section{Objetivo}

Explorar las experiencias en el uso de métodos de salud sexual y su relación con las Infecciones de Transmisión Sexual en mujeres lesbianas.

\section{Material y método}

Es un estudio cualitativo con diseño fenomenológico. Su enfoque se basa en el desarrollo real de los hechos. ${ }^{[10] .}$ Con una muestra de 10 participantes, las cuales cumplieron con los criterios de inclusión, el muestreo fue en cadena de tipo intencional que pretende seleccionar a los informantes según las necesidades detectada y por saturación. A las participantes se les explica en que consiste su participación en la investigación, los riesgos y beneficios de ésta. Para fines de confidencialidad y análisis de resultados, las participantes se identificaron como P1, P2, P3... P10. Las participantes decidieron la fecha, lugar y hora para su entrevista. Firman consentimiento informado. Durante la entrevista se utilizó una grabadora de vos y entrevista semi-estructurada, la cual está conformada por 13 interrogantes abiertas Para el análisis de contenido de la transcripción literal de las grabaciones se identificaron expresiones significativas que presentaron mayor poder descriptivo, seguido de la identificación de categorías y subcategorías.

\section{Resultados}

Los datos obtenidos a través de las entrevistas semiestructuradas fueron procesados mediante codificación cualitativa. El estudio se conformó con 10 mujeres de edades de 23 a 43 años.

Se estructuraron categorías y subcategorías:

\section{Conocimiento de métodos de salud sexual}

a) Uso de métodos de salud sexual

b) Tipos de métodos de salud sexual

\section{Salud sexual}

a) Prácticas de autocuidado en la sexualidad

b) Conocimiento de prevención de ITS

3. Sentimientos y experiencias de la sexualidad

a) Placer y excitación sexual

\section{Acercamiento al profesional de salud}

a) Promoción a la salud sexual

Iniciando con el análisis y la interpretación de los datos obtenidos en la investigación, se consideró que las experiencias de lesbianas respecto al uso de métodos de salud sexual y la relación con las ITS es de gran importancia ya que el profesional de enfermería cumple una importante labor preventiva como profesional de salud al interactuar con la mujer lesbiana, se le brinda además de la información, apoyo y orientación para que exprese sus dudas, temores, inquietudes, sentimientos, expectativas, lo que favorece personalizar el contenido informativo y que sean ellas quien tomen decisiones a favor de su salud sexual de tal forma que sus enseñanzas las oriente a responsabilizarse activamente en la conservación de la salud, en este caso a prevenir una ITS, incluyendo el VIH/SIDA [4]. 


\section{1) Conocimiento de Métodos de Salud Sexual}

Es importante conocer el conocimiento que tienen las mujeres lesbianas con las experiencias que han tenido y vivido con los métodos de salud sexual. Cuando se habla de conocimiento se refiere al grado de entendimiento sobre información basada en conocimiento científico y que se obtiene a partir de la interacción y observación del mundo, es mejor conocido como conocimiento empírico.

$\checkmark \quad$ Participante 1... "Los métodos son aquellos que para que uno como persona tenga esa protección y tenga esa prevención de contraer una infección."

$\checkmark$ Participante 2... "El método es como por ejemplo un condón para que tu no contraigas o te contagies de una enfermedad de transmisión sexual como por ejemplo sífilis o gonorrea."

$\checkmark \quad$ Participante 4... "Un método de salud sexual yo creo que son como los condones o los dedales que nosotras usamos y así evitar una ITS."

A través de los discursos emitidos por las participantes de la investigación se considera que ellas a través de su conocimiento empírico su grado de información sobre la conceptualización de un método de salud sexual es considerablemente alto, las participantes coinciden en que un método de salud sexual es una protección para el cuidado y prevención de una infección de transmisión sexual.

\section{a) Uso de Métodos de Salud Sexual}

Disfrutar el sexo es lo mejor, por eso es muy importante que se mantenga la higiene y salud del cuerpo y hablar de sobre el uso de los métodos de salud sexual en lesbianas es ampliamente un mundo de experiencias y vivencias. El uso de preservativos masculinos como único método de cuidado a invisibilizado a las lesbianas y la sexualidad de las lesbianas; aún es un tema cerrado no sólo a nivel social, sino también desde la realidad de las políticas públicas ${ }^{[11] .}$

Comúnmente, se piensa que las relaciones sexuales entre lesbianas carecen de riesgos y contagio de infecciones. La visión, asociada a la ausencia de penetración fálica y a las posibilidades de embarazo, ha descansado sobre mitos, poniendo en riesgo la salud de la comunidad lésbica ${ }^{[11]}$

$\checkmark \quad$ Participante 1... "pues como tal no uso algún método en específico cuando tengo relaciones sexuales, sin embargo como te decía, creo que es importante que sean utilizados."

$\checkmark$ Participante 7... "Mira yo te voy a decir algo, en realidad no es como que las lesbianas usemos tanto los métodos de protección porque llegamos a pensar que no habrá como tal un embarazo, pero, si es importante que los conozcamos, más que nada por protección y es que además si tú vas al sex shop son caros y algo difíciles de adquirir."

$\checkmark \quad$ Participante 8... "Mi experiencia con el uso de métodos pues que te diré, en lo personal no me gusta porque como que no se disfruta y además no es algo como que lo consigas así a la vuelta de la esquina."

De acuerdo con los argumentos de éstas mujeres lesbianas en cuanto al uso de métodos de salud sexual es muy evidente que la protección que tienen al tener relaciones sexuales con otras mujeres es poca y uno de los principales factores que se asocian es lo económico, debido a que el acceso a éstos no es muy factible y además prefieren no usarlos debido a que sin ellos les es más placentera su relación sexual.

\section{b) Tipos de métodos de salud sexual}

Todos, absolutamente todos, estamos en riesgo de contraer una infección de transmisión sexual si se tiene sexo sin protección. Las ITS más frecuentes 
entre las mujeres son: la tricomoniasis, el papiloma humano, las candidiasis, las clamidias, la vaginosis bacteriana y el herpes genital, además del VIH. Algunas de estas infecciones a veces, no ocasionan síntomas y resultan verdaderamente peligrosas ya que pueden provocar infertilidad $y$, además, deben tratarse las dos partes de la pareja para solucionar el problema. ${ }^{[11]}$

Para ello han surgido al mercado diferentes tipos de métodos de salud sexual que son de utilidad para las prácticas sexuales entre lesbianas, algunas de ellas por mencionar incluyen los dedales que sirven para ser colocados en los dedos y así evitar contraer una ITS, también existen los diques dentales, barreras de látex, cuadros de látex o protectores de látex que sirven para ser colocados en la vagina o el ano durante las prácticas sexuales como cunnilingus.

Hay que tener en cuenta que las relaciones entre mujeres lesbianas no están libres de dichas enfermedades, ya que el riesgo no estriba en la sexualidad de cada uno si no que varía dependiendo de las prácticas sexuales y número de parejas de cada individuo.

$\checkmark$ Participante 2... "Pues yo solo conozco el condón y los dedales de ahí en fuera no tengo conocimiento de otro... ah y hay una como tela o maya que se pone en la vagina para sexo oral, nunca los he utilizado pero son los que yo conozco"

$\checkmark \quad$ Participante 3... "Solo eh utilizado el condón femenino pero como te digo fue solo una vez que lo utilice y pues a mí y a mi pareja no nos gustó tanto que digamos y en realidad lo avente (risas), es que de verdad no es muy excitante, como que no se disfruta, se necesita de ese contacto real en los roces (risas) y de ahí en fuera pues también hay protección de látex y dedales y diques, pero bye con ellos." $\checkmark$ Participante 4... "fijate que los dedales los compré y fue desperdicio de dinero porque te los pones (muestra su mano) y al momento de utilizarlos se me llegó a salir uno y pues no le veo tanta gracia, conozco la barrera de látex para hacer sexo oral, intente hacer uno pero real, fue un fracaso, se resbala mucho de la vagina."

$\checkmark \quad$ Participante 10... "yo tengo un dildo y es el que utilizo con mi pareja de vez en cuando, como tal dedales o método de barrera pues no utilizo, ningún otro método como por ejemplo he escuchado de los cuadritos de látex que se ponen en los genitales para el oral pero pues nunca."

Las mujeres lesbianas entrevistadas mencionaron conocer diferentes tipos de métodos de salud sexual que son utilizados durante las prácticas sexuales incluso solo tres han utilizado de una manera poco frecuente, sin embargo el resto de las participantes solo las conoce pero no son utilizados en sus actos sexuales incluso refieren que es ideal que sean utilizados, pero por cuestiones placenteras y económicas y de muy poco acceso a ellos son evitados

\section{2) Salud Sexual}

Cuando se habla de salud sexual nos referimos a sentirnos bien con nuestra sexualidad y gozar de ella, siguiendo unos principios de respeto hacia uno mismo y hacia las demás. También implica ser conscientes de la capacidad de disfrutar y darnos el permiso a esta posibilidad, y poder identificar $y$ manejar emociones que nos puedan afectar (vergüenza, miedos, culpas...), que puedan deteriorar el gozo y disfrute en nuestras relaciones sexuales ${ }^{[8]}$.

$\checkmark \quad$ Participante 3... "Salud sexual, pues entra todo el tema de las enfermedades de 
transmisión sexual y por eso mismo pues creo que es importante cuidarnos."

$\checkmark$ Participante 6... "pienso que tener salud es tener que cuidarse porque algunas enfermedades son como para siempre como el VIH y entonces si nosotras utilizamos de manera adecuada los métodos que dices. pues habría menos enfermedades y más salud sexual en este caso"

$\checkmark$ Participante 9... "Tener relaciones sexuales entre mujeres implica ese momento en el que tu como persona te sientes libre de todo y más cuando tú y tu pareja saben que gozas de plena salud y bienestar sin miedo a que contraigas una ITS"

\section{a) Prácticas de autocuidado en la sexualidad}

El comportamiento sexual se considera una práctica por el hecho de ser construido y compartido socialmente, lo que remite a la elaboración de las imágenes, sentidos y significados atribuidos al ejercicio de la sexualidad. En este sentido, las prácticas sexuales se definen como "patrones de actividad sexual presentados por individuos 0 comunidades con suficiente consistencia para ser predecibles" [12].

Las conductas sexuales de riesgo han despertado gran interés debido a que hacen más probable la incidencia de situaciones nocivas para la persona. Tener relaciones sexuales sin condón o haber consumido alcohol o la promiscuidad, hacen vulnerables a las personas frente a las amenazas referidas. ${ }^{[12]}$

$\checkmark \quad$ Participante 1... "mientras esté bien bañadita y que todo ahí este limpio, adelante, ya que yo no uso algún método de protección" $\checkmark \quad$ Participante 6... "pues el condón, sirve como barrera, yo sé que se corta de un lado y cuando haces sexo oral, se coloca en la vagina y así no hay contacto directo con la lengua y vagina"

$\checkmark$ Participante 9... "yo siempre procuro que cuando voy a tener relación sexuales, evitemos que ambas estemos en nuestro periodo, ah y de vez en cuando usamos un condón"

Con respecto a lo anterior, las prácticas de autocuidado dentro de la salud sexual van más allá de usar un método de salud sexual o mantener una higiene, dentro de los argumentos es evidente que las mujeres lesbianas no llevan un adecuado autocuidado, es aquí la importancia de que los profesionales de la salud, en especial enfermería se encargue de brindar la orientación e información necesaria para llevar a cabo una buena práctica de prevención de ITS, cabe mencionar que hay prejuicios por parte de los profesionales de la salud y de las lesbianas para brindar y recibir asistencia, lo que provoca efectos perjudiciales en la salud sexual de éstas mujeres.

\section{b) Conocimiento y prevención de ITS}

De acuerdo a la NOM-039 para la prevención y control de las infecciones de trasmisión sexual, son aquellas que se trasmiten en forma predominante o exclusiva por contacto sexual ${ }^{[4]}$. Entre las ITS se tiene a: Sífilis, Gonorrea, Chancro, Herpes, Tricomoniasis, Vaginitis Bacteriana, Papiloma Humano, SIDA.

Las ITS han aumentado considerablemente. Las razones son entre otras: un comienzo más precoz de las relaciones sexuales, el turismo y mayor movilidad geográfica, la escasa información y formación sexual, la carencia de centros especializados etc. ${ }^{[13]}$.

Los determinantes de la epidemiología de las ITS son tan multifacéticos como deberían ser los enfoques de prevención y asistencia. Las medidas de intervención 
encaminadas a impedir la propagación de ITS y de la infección por el VIH deben elaborarse teniendo en cuenta la fisiología humana, las modalidades de comportamiento humano y las influencias Participante 4....'Los métodos son aquellos que para que uno como persona tenga esa protección y tenga esa prevención de contraer una infección"... "como los condones o los dedales que nosotras usamos y así evitar una ITS"

$\checkmark$ Participante 5... "las infecciones son un problema grandísimo para la salud, porque están a la orden del día, no se diga el SIDA o la gonorrea, que se yo, por eso es importante cuidarnos"

$\checkmark$ Participante 7... "definitivamente me da miedo contraer una ITS, yo creo que todas, y por ejemplo yo solo con estar bien bañadita con eso basta, ah un condón que no falte nunca (risas), al rato me contagian de gonorrea o sífilis y para que quieres"

$\checkmark \quad$ Participante 8... "pues si estoy consciente de que pueda tener una ITS porque como te digo no acostumbro a protegerme o tener esta parte de prevenir, sin embargo pues trato siempre de estar limpia de todo"

Respecto a los argumentos emitidos por las participantes, es evidente que las mujeres lesbianas aplican muy pocas medidas de prevención ante una infección de transmisión sexual, siendo esto que el riesgo de contraer un es relativamente alta, la prevención para el profesional de enfermería es sumamente fundamental, así ellas pueden exponer sus dudas, opiniones y experiencias con respecto a su sexualidad, por ello la importancia de informar, orientar y prevenir las infecciones de transmisión sexual en mujeres lesbianas.

\section{3) Emociones y sentimientos de la Sexualidad}

La emoción es una palabra de lenguaje común, se aplica en la psicología a una reacción afectiva de intensidad bastante grande, dependiente de los centros diencefálicos, y que engloba normalmente unas manifestaciones de orden vegetativo. ${ }^{(14)}$

Las emociones fundamentales, comprenden la alegría y la pena (dolor), el miedo y la ira, el amor y el disgusto. Las emociones son pasajeras, y tienen reacciones corporales, por ejemplo, la sudoración, la dilatación pupilar. Los sentimientos son elementos que perduran por mucho tiempo. ${ }^{(15)}$

Cuando un hombre o mujer tiene "sentimientos sexuales" hacia otro, se despierta una aspiración de intimidad y amor, que incluye la expresión de la ternura, una añoranza de estar cerca de la persona y el deseo de manifestarse vulnerable, es decir, abierto emocionalmente, capaz de ofrecer un ambiente cálido y seguro. Estos sentimientos sexuales llegan a su clímax cuando ocurre el abrazo íntimo, o sea el coito. (16)

No obstante, la pura excitación genital, ocurre sin sentimientos hacia la otra persona. De hecho no se ve al otro como persona, sino como un objeto sexual del cual se puede sacar provecho, una satisfacción momentánea y un triunfo para el ego narcisista que niega los sentimientos del otro y lo somete para sentirse él superior. ${ }^{(16)}$

En la prueba de valores de Hartman, desarrollada a nivel clínico por el doctor Salvador Roquet (19201995), se establecen tres dimensiones de la sexualidad: la emocional-afectiva, la bioenergética y el espacio temporal, que involucra los momentos de intimidad. De esta manera podemos mirar que la sexualidad es un sistema de realización del ser donde están involucrados el amor, la ternura, la capacidad de conexión biocorporal, y la preparación de la intimidad en un tiempo y espacio determinados, que impide que la relación íntima se vuelva algo impulsivo. (16)

Participante 2... "definitivamente me encanta estar con mi pareja porque la amo mucho y me entrego mucho a ella" 
$\checkmark$ Participante $4 \ldots$ "simplemente siento muchísima más atracción con estoy con mi novia, ella es muy tierna cuando tenemos relaciones y me hace sentir muy apasionada y muy excitada, no sé cómo decírtelo, pero de verdad es tan placentero estar con ella"

$\checkmark$ Participante 5 ... "siempre he dicho que nunca es lo mismo coger que hacer el amor, cuando tu haces el amor es estar plenamente entregado a tu pareja, porque en verdad la amas y la vas a respetar $y$ vas a confiar en ella, y durante la relación sexual vas a sentir esta parte de que te encuentras feliz de estar con tu pareja, gozando de plena sexualidad"

$\checkmark$ Participante 8... "un simple beso que me den o un abrazo, con eso es suficiente para que me demuestren su cariño, afecto y amor, no me la voy a pasar teniendo sexo todo el tiempo, porque eso no es un buen amor, amor es que te quieran de verdad y den todo por ti, en todo momento"

$\checkmark \quad$ Participante 10..."Pasión, amor, excitación y ternura es lo que siento, no hay vuelta de hoja, en verdad me hace sentir plena $y$ satisfecha con lo que hago, ¿será porque amo mucho estar con ella? Yo creo que si”

En relación a los testimonios de las participantes, las emociones y sentimientos de la sexualidad están presentes a lo largo de toda la vida y varía según las diferentes etapas vitales. Comprende el sexo, el erotismo, el placer, la identidad de género, la orientación sexual, la intimidad, los vínculos afectivos, el amor y la sexualidad se interrelaciona del tal manera con la personalidad, que se practica y se expresa en todo lo que somos.

\section{a) Placer y Excitación Sexual}

El placer sexual comprende las distintas sensaciones agradables y placenteras asociadas a las experiencias sexuales. A menudo, estas sensaciones se producen por el contacto sexual; otras veces surgen por pensamientos y fantasías. ${ }^{(17)}$

El placer sensual se refiere a un sentimiento concreto de placer que se desencadena por muchas de las actividades que los cuidadores utilizan para consolar y expresar afecto hacia los infantes, y que éstos a su vez utilizan para consolarse a sí mismos. Cuando el estado afectivo de placer sensual domina la experiencia, puede servir como "interruptor", el resultado puede ser una disminución de la tensión que dé lugar a la relajación o al incremento de la sensación que dé lugar a la excitación sexual. La excitación sexual se refiere a un sentimiento concreto de estimulación incrementada que progresa hasta niveles orgásmicos.

La excitación sexual, al igual que el placer sensual, se desencadena por muchas de las actividades que los cuidadores emplean para consolar y expresar afecto y que los niños utilizan para consolarse. ${ }^{(18)}$ Excitación sexual. Se entiende como la primera parte de la respuesta sexual. Durante la excitación sexual tanto el hombre como la mujer experimentan un aumento del ritmo cardiaco. La excitación comienza con la estimulación tanto física como psicológica o una combinación de ambas, ya sea a través del olfato, la vista, el tacto, el pensamiento o las emociones. En términos fisiológicos, se relaciona con el fenómeno vaso congestivo: flujo de sangre en ciertas regiones del cuerpo, particularmente en los órganos pélvicos. (18)

$\checkmark$ Participante 3... "Tener relaciones sexuales con mi pareja, es como hacer un viaje al universo"

$\checkmark$ Participante 4... "Para mi esa sensación de excitación y llegar a ese punto de tener un orgasmo es lo más increíble que me puede pasar, sin duda una experiencia sensacional"

$\checkmark$ Participante 5... "Me excita que me toquen, me besen, esa parte de llegar a sentir tanto placer me relaja un buen, te olvidas de todo, y es un 
momento de la vida que me hace sentir estar

flotando como en una nube, así bien chido"

A través de los discursos emitidos por las participantes, se comprende que ellas entienden que tener el buen sexo es el resultado de comprender como funciona su cuerpo, todas las participantes experimentan de manera diversa su placer sexual y disfrutan de cosas diferentes cuando se trata de relaciones sexuales.

\section{4) Acercamiento al Profesional de Salud}

El profesional de la salud o personal sanitario son todas las personas que llevan a cabo tareas que tienen como principal finalidad promover la salud. Deben estar preparados para hacer frente a retos como el envejecimiento de la población. Las nuevas enfermedades y el aumento de la carga de las ya existentes.

Por lo que el acercamiento con el profesional de salud debe considerarse como la primera opción de asesoramiento o seguimiento de la enfermedad para evitar caer en mitos o agravar el problema en esta ocasión de infecciones de trasmisión sexual.

Por lo contrario a la literatura y de acuerdo a la recolección de datos de las entrevistas realizadas se ve evidenciado en los siguientes discursos emitidos por las mujeres lesbianas

$\checkmark \quad$ Participante 2... "la verdad no me gusta ir a los hospitales o centros de salud, como le llamen, porque estoy mucho rato ahí sentada y me aburro"

$\checkmark \quad$ Participante 3... "la neta me da flojera ir a que me den platiquitas de eso (risas) porque en realidad todo te nace y con las personas que te rodean ellas te hablan y así se va haciendo una cadenita"

$\checkmark$ Participante 7... "una vez en la escuela fueron unas enfermeras o doctoras y nos hablaron de las enfermedades de trasmisión sexual, pero como tal que yo vaya a que me hablen de este tipo de temas pues no"

\section{a) Promoción a la Salud Sexual}

La promoción de la salud es un tema que cobra vigencia en la actualidad, en razón a que se constituye en una estrategia básica para la adquisición y el desarrollo de aptitudes o habilidades personales que conlleva a cambios de comportamiento relacionados con la salud y al fomento de estilos de vida saludables, así contribuye al mejoramiento de la calidad de vida de las personas que conforman una sociedad. ${ }^{[19]}$ De modo que promoción a la salud sexual es el proceso por el cual se le brinda la información necesaria a la población con el fin de prevenir o mejorar las condiciones en las que se encuentre relacionado a sus necesidades sexuales.

Respecto a lo anterior y haciendo un análisis de los datos obtenidos a través de las entrevistas, las mujeres lesbianas han recibido por lo menos una orientación o información necesarias para mejorar su salud sexual con el fin de que ellas se responsabilicen de tener un control de ellas mismas en relación a su sexualidad. Esto, se ve evidenciado en los siguientes argumentos:

$\checkmark$ Participante 1 ... "pues cuando llego a ir al centro de salud, si me hablan de protegerme y hasta me dan condones"

$\checkmark$ Participante 2... "del ratote que me llego a quedar ahí sentada luego me llegan a dar folletos o trípticos sobre prevención de enfermedades, y que hacer, cosas así para prevenir"

$\checkmark \quad$ Participante 6... "fijate que a mí en lo particular si me gusta que me hablen de eso, porque conoces nuevas cosas que tal vez tu no sabías, insisto el prevenir mejora tu salud tanto física, mental, emocional y pues sexual ¿no?" 
De acuerdo a los testimonios de las participantes, ellas han recibido por lo menos una vez en su vida, orientación en relación a su salud sexual, es importante que los esfuerzos destinados a la promoción de la salud sexual, tiene mayor eficacia si se toma en cuenta todos los elementos de la sexualidad, por medio de la inclusión de todas sus dimensiones, sin distinción de género, raza, vínculos, preferencias o cultura ${ }^{[19]}$

\section{Discusión y Conclusión}

Es importante conocer el conocimiento que tienen las mujeres lesbianas con las experiencias que han tenido con los métodos de salud sexual. No todas las lesbianas viven la sexualidad de la misma manera y no existe una sola forma de practicar el sexo, se puede disfrutar y jugar según el momento: las ganas, deseos y preferencias de cada lesbiana puede variar en cada encuentro sexual ${ }^{[8]}$.

En un estudio de Frómeta y Ponce ${ }^{[20]}$ se encontró que las participantes construyen su sexualidad como parte de reconocer y asumir su identidad de mujer lesbiana, además demuestra que gran parte de ellas se encuentran satisfechas con su sexualidad y de igual manera presentan conductas de riesgo y no realizan acciones de autocuidado se encuentran semejanzas en que las mujeres lesbianas reconocen e identifican que tener salud sexual va más allá de hablar de protección y enfermedades de transmisión sexual, sin que es meramente el reconocer y asumir su sexualidad, sin embargo, hablando clínicamente, ellas presentan de igual manera riesgos de contraer una infección de transmisión sexual y el autocuidado que realizan no es lo suficiente para hacer de su salud algo estable y de bienestar, de igual manera hay similitud en que el profesional de salud es deficiente en cuanto a cobertura de información sobre prevención y autocuidado de ITS en mujeres lesbianas.
Gómez Bedolla y Insuasti Moncayo señalan en los resultados del estudio que realizaron, primeramente que dentro de las necesidades que encuentran las participantes en los servicios de Salud Sexual y Salud Reproductiva (SS-SR) está presente la búsqueda de reconocimiento en todo lo referente a la orientación y diversidad sexual: en las prácticas sexuales entre mujeres, así como también los factores de riesgo, prácticas de prevención. En cuanto a las actitudes percibidas en la atención por parte del personal de salud, se halló que existen también diferencias en la visualización de las participantes hacia los trabajadores sanitarios en relación al tipo de afiliación al sistema de salud, a diferencia de este estudio en el que las participantes no se acercan a los profesionales de salud para su orientación en temas salud sexual, y se observa que no es muy común que estas mujeres lesbianas utilicen algún método de salud sexual para la prevención de una infección de transmisión sexual.

En otro estudio ${ }^{[22]}$ arrojó que el mayor obstáculo para el acceso a servicios de salud sexual en mujeres lesbianas está en las lógicas de invisibilización que se traduce en la discriminación sentada en el marco del contexto lesbofobica, la falta de producción teórica y la ausencia de preocupación practica sobre relaciones sexuales entre mujeres y la invisibilidad de las lesbianas como colectivo, aquí se coinciden en que los servicios de salud al igual han excluido la preocupación por brindar información sobre la prevención de ITS en mujeres lesbianas, además de la inclusión de la orientación e información sobre el uso de métodos de salud sexual en este grupo de personas. A diferencia de nuestras participantes, ellas están más interesadas por asistir o recibir alguna platica sobre salud sexual y métodos de salud sexual, en este estudio las mujeres lesbianas presentan poco interés por acercarse a los servicios de salud para orientación sexual, por lo que la 
probabilidad de padecer una ITS es más alta debido al poco acercamiento.

Actualmente la formación profesional con conocimiento de la vida sexual de las mujeres lesbianas, constituye un elemento invisible en las políticas de salud, al igual que el tema de la orientación sexual como comportamiento social a tener en cuenta en los procesos salubristas, dado por la inadecuada formación de recursos humanos y de cobertura de información acerca de la salud sexual de las mujeres lesbianas en los servicios médicos, estructurado sobre un modelo androcéntrico y homofóbico.

Se hace necesario que los profesionales de salud adquieran conocimientos y formación en sexualidad, orientaciones sexuales e identidades de género, prácticas sexuales, en la temática de lésbico, gay, bisexual, transexual, (LGBT), para que comprendan que existen orientaciones sexuales e identidades de genero diversas, así como prácticas sexuales diversas que no necesariamente son definidas a partir de una orientación sexual y se puedan prevenir enfermedades de transmisión sexual.

\section{Referencias}

[1] Soto Gyzman MA, Barrios Aranda F (dir) Aceptacion hacia personas con preferenciasexual distinta [tesis en linea] [Quetzaltenango] Universidad Rafael Landivar; 2012 [citado 16 de julio 2018] Recuperado en: http://biblio3.url.edu.gt/Tesis/2012/05/42/Soto-Maria.pdf

[2] Organización Mundial de la Salud. Infecciones de Transmisión Sexual. [en línea] OMS 2016 [citado 20 de julio 2018] Recuperado n: http://www.who.int/es/news-room/fact-sheets/detail/sexuallytransmitted-infections-(stis)

[3] Instituto Nacional de las Mujeres. Mujeres, transformando el futuro. [en línea] gob.mx. (s.f.) [citado 20 de agosto 2018] Recuperado en: https://www.gob.mx/inmujeres

[4] Diario Oficial de la Federacion. Norma Oficial Mexicana NOM039-SSA2-2014, Para la prevención y control de las infecciones de transmisión sexual [en línea] NOM-039 2014 [citado 30 de julio 2018] Recuperado en: https://www.gob.mx/cms/uploads/attachment/file/227625/NORMA Oficial_Mexicana_039_DOF 01-05-17.pdf

[5] S/A Mujer contra mujer:El lesbianismo tiene más componentes afectivos que genitales. Revista Somos Jovenes. La Habana . [en línea] 2015 [citado 15 de noviembre 2018]393 Recuperado en: http://www.somosjovenes.cu/articulo/mujer-mujer
[6] Diario Oficial de la Federacion. Norma Oficial Mexicana NOM017-SSA2-2012, Para la vigilancia epidemiológica [en línea] NOM017 -2013 [citado 02 de noviembre 2018] Recuperado en: http://dof.gob.mx/nota_detalle.php?codigo $=5288225 \&$ fecha $=19 / 02 / 20$ 13

[7] Gayet, C. Infecciones de Transmicion Sexual en Mexico: Una mirada desde la historia y el genero. [en línea] Secretaria de SaludMéxico, 2015 Censida [citado 02 de noviembre 2018] Recuperado en:

http://www.censida.salud.gob.mx/descargas/biblioteca/ITS en Mex una mirada.pdf

[8] Fundacion Triangulo Madrid. Guia de salud sexual para mujeres que tienen sexo con mujeres. [en línea] 2017 Fundacion Triangulo Madrid. [citado 07 de noviembre 2018] Recuperado en: https://assirmn.files.wordpress.com/2017/03/guia-de-saludlesbianisme.pdf

[9] Choccare Salcedo CC. Lema Morales J. (dir) Nivel de conocimientos sobre las infecciones de transmisión sexual-VIH/SIDA y sus medidas preventivas en los estudiantes de enfermería de la UNMSM [tesis en linea] [Perú] Universidad Nacional Mayor de San Marcos; 2008 [citado 16 noviembre 2018] Recuperado en: http://cybertesis.unmsm.edu.pe/bitstream/handle/cybertesis/521/chocc are sc.pdf;jsessionid=B6E5A5263FB5A3E0103C554E3DCED994?s equence $=1$

[10] Hernandez R. Fernandez C, Baptista P. Metodologia de La Investigacion. 6ta Edicion. México, D.F: McGraw-Hill. 2014 .600 p

[11] Vargas Rojas V. Protección sexual lésbica: De la invisibilización del Estado al tabú social. [en línea] 2015 [citado 18 de enero 2019] Recuperado en:https://www.eldesconcierto.cl/2015/07/23/proteccionsexual-lesbica-de-la-invisibilizacion-del-estado-al-tabu-social/

[12]Bahamón Muñetón MJ, Vianchá Pinzón MS, Tobos Vergara AR. Practicas y conductas sexuales de riesgo en jovenes: una perspectiva de género.Psicologia desde el Caribe [en línea] 2014 [citado 10 de enero 2019];31(2) Recuperado en http://www.scielo.org.co/scielo.php?script=sci_arttext\&pid=S0123 417X2014000200008

[13]Gutiérrez León MA, Haro Álvarez L, Armas González C, Capote Pestano L, et al. Programa de prevención de ITS y SIDA: Guía educativa para un sexo más seguro [en línea] 2004 [citado 22 de febrero 2019] Recuperado en:

http://www.sidastudi.org/resources/inma gic-img/dd0467.pdf

[14 ]Wukmir VJ. La emoción. [en línea] 1967 [citado 17 de marzo 2019] Recuperado https://www.biopsychology.org/wukmir/eys/eys 2. htm

[15] Pérez Conchillo M. Emociones y sexualidad. . [en línea] 2010 [citado 22 de marzo 2019] Recuperado en:

https://wwwuned.es/saludsexual/sx.html/EMOCIONES\%20Y\%20SE XO\%20AVILA.pdf

[16] Rodiles J. Sentimientos sexuales o excitación. . [en línea] 2013 [citado 26 de marzo 2019] Recuperado en: https://janinepsicologia.wordpress.com/2013/10/03/sentimientossexuales-o-excitacion-genital/

[17] Zanzu. El placer sexual . [en línea] s/f [citado 12 de abril 2019] Recuperado en: https://www.zanzu.de/es/la-sexualidad/el-placersexual/que-es-el-placer-sexual/

[18] Lazar S, Licthenberg, J. D. Placer sensual, excitación sexual y feminidad: apreciar la respuesta sexual femenina. Rev Psicoanalisis Aperturas[en línea] 2003 [citado 25 de abril 2019]; 23(4) 592-614. Recuperado http://www.aperturas.org/articulo.php?articulo $=0000347$ 
[19] Giraldo Osorio A, Toro Rosero MY, Macías Ladino AM, Valencia Garcés CA, Palacio Rodríguez S. La Promoción de la salud como estrategia para el fomento de estilos de vida saludables. Revista Hacia la Promoción de la Salud [en línea] 2010 [citado 20 de abril 2019];15(1);128-143. Recuperado en: http://www.redalyc.org/pdf/3091/309126693010.pdf

[20] Frómeta Rodriguez O, Ponce Laguardia, T. Salud sexual y desarrollo de la sexualidad de mujeres lesbianas en edad adulta. Revista sexologia y sociedad. [en línea] 2013 [citado 25 de abril 2019];19(2):.102-115. Recuperado en: http://revsexologiaysociedad.sld.cu/index.php/sexologiaysociedad/arti cle/view/190

[21] Gomez Bedoya E, Insuasti Moncayo A. Orcasita Pineda (dir) Servicios de salud sexual y salud reproductiva: experiencias de un grupo de mujeres lesbianas y bisexuales. [tesis en linea] [Javeriana]: Pontificia Universidad Javeriana; 2018 [citado 25 de mayo 2019].. Recuperado

en:

http://vitela.javerianacali.edu.co/handle/11522/10423?show=full

[22] Brown J,Pecheny M, Tamburrino MC, Conde LL, Perrotta GV, Capriati A, Andia AM, Mario S, Ibarlucia I. Atención ginecológica de lesbianas y bisexuales: notas sobre el estado de situación en Argentina. Interface [en linea] 2014 [citado 15 de junio 2019]; 18(51): Recuperado

http://www.scielo.br/scielo.php?script=sci_arttext\&pid=S1414$\underline{32832014000400673}$ 